\title{
Influence of Shell Parameters on Optical Properties of Spherical Metallic Core-Oxide Shell Nanoparticles
}

\author{
Victor K. Pustovalov ${ }^{1}$ and Liudmila G. Astafyeva ${ }^{2}$ \\ ${ }^{1}$ Belarusian National Technical University, Nezavisimosti Prospect 65, 220013 Minsk, Belarus \\ ${ }^{2}$ B.I. Stepanov Institute of Physics, National Academy of Sciences of Belarus, Nezavisimosti Prospect 68, 220072 Minsk, Belarus \\ Correspondence should be addressed to Liudmila G. Astafyeva; astafev@dragon.bas-net.by
}

Received 30 December 2014; Accepted 21 January 2015

Academic Editor: Ottorino Ori

Copyright (c) 2015 V. K. Pustovalov and L. G. Astafyeva. This is an open access article distributed under the Creative Commons Attribution License, which permits unrestricted use, distribution, and reproduction in any medium, provided the original work is properly cited.

\begin{abstract}
Different metal homogeneous nanoparticles have been extensively studied in recent years due to their wide range of potential applications. It is very interesting to investigate core-shell nanoparticles with oxide shell from core metal. The formation of oxide shell on metallic nanoparticles can be achieved by different chemical and physical methods including also natural oxidation of pure metallic nanoparticles in gaseous or liquid media, containing oxygen components (air, water, etc.). We numerically calculated efficiency factors of absorption $K_{\text {abs }}$, scattering $K_{\text {sca }}$, and extinction $K_{\text {ext }}$ of radiation with wavelength $\lambda$ in the spectral interval

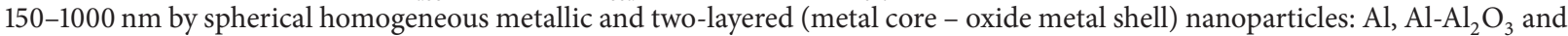
$\mathrm{Zn}, \mathrm{Zn}-\mathrm{ZnO}$ with core radii in the range $5-50 \mathrm{~nm}$ and shell thickness $5 \mathrm{~nm}$. Analysis of presented results has been carried out.
\end{abstract}

\section{Introduction}

Recent advances in photothermal nanotechnology based on the use of nanoparticles (NPs) and optical (laser) radiation have been demonstrated their great potential. In recent years the absorption and scattering of radiation energy by NP have become a great interest and an increasingly important topic in photothermal nanotechnology [1-27] (also see the references in these papers). There are many reasons for this interest in nanophotonics including applications of NPs in different fields, such as catalysis $[1,2]$, nanoelectronics $[3,4]$, nanooptics and nonlinear optics $[5,6]$, and energetic nanotechnology (e.g., photovoltaics [7] and light-to-heat conversion $[8,9])$. Laser applications in nanotechnology include laser nanobiomedicine [10-15] with determination of selected properties of NPs $[16,17]$ and laser processing of metallic NPs in nanotechnology [18-23]. Metallic NPs are mostly interesting for different nanotechnologies among other NPs.

In recent years, the optical properties of metal NPs have been under extensive research mainly due to their unique optical properties arising from the localized surface plasmon resonance (LSPR) [25-30]. The LSPR causes a relatively narrow absorption peak, which leads to high optical selectivity.
Most of the abovementioned technologies rely on the position and strength of the surface plasmon on a nanosphere and successful applications of NPs in nanophotonics are based on appropriate plasmonic and optical properties of NPs. High absorption of radiation by NPs can be used for conversion of absorbed energy into NP thermal energy, heating of NP itself and ambient medium, and following photothermal phenomena in laser and optical nanotechnology and nanomedicine. High scattering of radiation is used as a powerful tool in optical diagnostics and biological and molecular imaging.

Different metal (gold, silver, platinum, zinc, etc.) NPs have been extensively studied in recent years due to their wide range of potential applications [1-30]. Thermooptical analysis and selection of the properties of metal NPs for laser applications in nanotechnology were carried out in $[9,16,17,25-$ 30]. Metal NPs have their LSPR in the ultraviolet and visible spectral intervals of optical radiation. The possibility of controllably tuning the LSPR wavelength through the visible to near infrared region is very important and promising for the technological applications. Possible effective way of adjusting NP optical properties and shifting the LSPR peak position to near-infrared wavelength is to combine the metal NPs 
with dielectric material and by changing the NP geometrical parameters.

Recently, in addition to pure metal NPs also metaldielectric (dielectric-metal) core-shell NPs are studied for the improvement and manipulation of the plasmon resonances of $\mathrm{NP}$ properties. For example, $\mathrm{SiO}_{2}$-gold and gold- $\mathrm{SiO}_{2}$ coreshell NPs are widely investigated and applied in experiments $[10,16,31-33]$. The position of the LSPR for such core-shell NPs is strongly influenced by the presence of the geometrical characteristics: the core radius, the thickness of the oxide layer, and the ratio between them $[10,16,31-33]$.

But in many cases oxide (dielectric) shells are formed on the surface of metal NPs and we investigate core-shell NPs with oxide shell from core metal. The formation of oxide shell on metallic NP can be achieved by different chemical $[33,34]$ and physical [35] methods. The formation of thick oxide shell promotes the use of core-shell metal-oxide NPs in chemical nanotechnology. The presence of oxide shell on metallic NP surface can prevent the origination of chemical reaction on NP surface in chemical reactive atmosphere and further consequences that can be used in some technologies.

Natural oxidation of pure metallic NPs in gaseous or liquid media, containing oxygen components (air, water, etc.), leads to the formation of thin oxide shell with thicknesses of about 3-5 nm on metallic NPs and core-shell two-layered metallic-oxide NPs during short period of time. The action of intensive optical (laser) radiation and NP heating can cause oxidation of surface layer of metallic NP and the formation of oxide shell on NP. The laser processing of metallic NPs in air atmosphere can cause simultaneously increasing of oxide shell thickness on particle surface and its evaporation [35].

The fabrication and investigation of core-shell NPs formed by a metal core and its own oxide shell were carried out in [36-46]. For example, $\mathrm{Ag}-\mathrm{Ag}_{2} \mathrm{O} \mathrm{NPs}$ were investigated by physical and chemical methods in [36-39] and $\mathrm{Al}^{-\mathrm{Al}_{2} \mathrm{O}_{3}}$ NPs were experimentally investigated in [40-42]. Determination of the oxide layer thickness in core-shell zerovalent iron NPs was made in [43]. Investigation of microstructure control of $\mathrm{Zn}-\mathrm{ZnO}$ core-shell NPs was carried out in [44]; the surface plasmon resonance of $\mathrm{Cu}-\mathrm{Cu}_{2} \mathrm{O}$ core-shell NPs was studied in [45].

On the other side, a comparative analysis of the optical parameters of different metal-oxide NPs for using them as agents in laser nanotechnology is still missing. In this paper, we study systematically influence of shell parameters on optical properties of spherical metallic core-oxide shell Al$\mathrm{Al}_{2} \mathrm{O}_{3}, \mathrm{Zn}-\mathrm{ZnO}$ NPs using a computational method.

\section{Numerical Results and Discussions}

We numerically calculated the efficiency factors of absorption $K_{\text {abs }}$, scattering $K_{\text {sca }}$, and extinction $K_{\text {ext }}$ of radiation with wavelength $\lambda$ by spherical homogeneous and two-layered NPs on the base of Mie theory [26]. Numerical results are presented for cases of homogeneous metallic and two-layered (metal core, oxide metal shell) NPs: $\mathrm{Al}, \mathrm{Al}_{-} \mathrm{Al}_{2} \mathrm{O}_{3}$, and $\mathrm{Zn}, \mathrm{Zn}$ $\mathrm{ZnO}$. Values of optical indexes of refraction and absorption of metals, oxides, and surrounding media were used from [46-49]. Figures 1-4 presented below describe the dependencies of efficiency factors of absorption $K_{\mathrm{abs}}$, scattering $K_{\text {sca }}$, and extinction $K_{\text {ext }}$ for homogeneous (Figures 1(a)-1(c), 2(a) $-2(\mathrm{c}), 3(\mathrm{a})-3(\mathrm{c})$, and 4(a)-4(c)) and two-layered NPs (Figures 1(e)-1(l), 2(e)-2(l), 3(e)-3(l), and 4(e)-4(l)) on radiation wavelength, NP core radii, and shell thickness. The positions $\lambda_{\mathrm{abs}}^{\max }, \lambda_{\text {sca }}^{\max }$, and $\lambda_{\text {ext }}^{\max }$ of maximum values of efficiency factors of $K_{\mathrm{abs}}^{\max }, K_{\mathrm{sca}}^{\max }$, and $K_{\mathrm{ext}}^{\max }$ on $\lambda$ axis are denoted in Figures 1-4 by different vertical lines; locations $\lambda_{\mathrm{abs}}^{\max }$ of maximum value of absorption factor $K_{\mathrm{abs}}^{\max }$ on axis $\lambda$ are denoted by solid lines, $\lambda_{\text {sca }}^{\max }$, dashed lines and $\lambda_{\text {ext }}^{\max }$, dasheddotted lines in the case of different values of $\lambda_{\mathrm{abs}}^{\max }, \lambda_{\mathrm{sca}}^{\max }$, and $\lambda_{\mathrm{ext}}^{\max }$. In some cases solid lines denote the simultaneous locations of all maximums of efficiency factors. We investigated two situations, when NPs were placed into two different surrounding media, air and water.

The parameter $P_{1}$ is used for the description of the optical properties of NPs:

$$
P_{1}=\frac{K_{\mathrm{abs}}}{K_{\mathrm{sca}}}
$$

The parameter $P_{1}$ describes the correlation between absorption and scattering of radiation by NP.

Figure 1 presents the dependencies of the efficiency factors of absorption $K_{\mathrm{abs}}$, scattering $K_{\mathrm{sca}}$, and extinction $K_{\text {ext }}$ of radiation and the parameter $P_{1}$ on wavelength $\lambda$ for spherical homogeneous Al NPs with radii $r_{0}=10,25$, and $50 \mathrm{~nm}$; for two-layered core-shell $\mathrm{Al}-\mathrm{Al}_{2} \mathrm{O}_{3} \mathrm{NPs}$ with shell thicknesses $\Delta r_{1}=5 \mathrm{~nm}$ and core radii $r_{0}=5,20$, and $45 \mathrm{~nm}$ and $P_{1}$ for core-shell NP radii $r_{1}=10,25$, and 50; for $\mathrm{Al}-\mathrm{Al}_{2} \mathrm{O}_{3} \mathrm{NPs}$ with $\Delta r_{1}=5 \mathrm{~nm}, r_{0}=10,25$, and $50 \mathrm{~nm}$, and $P_{1}$ for $r_{1}=15$, 30 , and $55 \mathrm{~nm}$. NPs are placed in air.

The formation of oxide shell on NP with substitution of surface metal layer by oxide layer with approximately equal thickness because of natural oxidation in air atmosphere is presented in Figures 1(e)-1(h). The influence of the formation of oxide shell on metal NP with equal radii $r_{0}=10 \mathrm{~nm}=$ $r_{0}+\Delta r_{1}=10 \mathrm{~nm}$ leads to next consequences. The plasmon maxima are created and shifted to bigger values of the wavelength. Figures 1(i)-1(l) present the influence of the increasing oxide shell thickness on metal core with $r_{0}=$ const in chemical gaseous atmosphere. It leads to a decrease of factors $K_{\mathrm{abs}}^{\max }$ for $r_{0}=10 \mathrm{~nm}$ and small influence for all optical factors for $r_{0}=25,50 \mathrm{~nm}$. The values of the parameter $P_{1}$ decrease with increasing $r_{0}\left(r_{1}\right)$ and increase with increasing wavelength bigger than $300 \mathrm{~nm}$. The formation of oxide shell on metal NP leads to decreasing $P_{1}$ in the spectral interval 150$300 \mathrm{~nm}$ for all values of $r_{0}$. The formation of oxide shell on metal core with $r_{0}=10 \mathrm{~nm}$ leads to significant decreasing of the values of $P_{1}$ for all spectral interval $150-1000 \mathrm{~nm}$ (Figure 1(l)). The increase of $r_{0}$ for homogeneous and coreshell NPs and increase of oxide shell thickness leads to increase of $K_{\text {sca }}, K_{\text {ext }}$ in comparison with $K_{\text {abs }}$.

The dependencies of efficiency factors of $K_{\mathrm{abs}}, K_{\mathrm{sca}}$, and $K_{\text {ext }}$ on $\lambda$ for fixed values of homogeneous radii and core radii $r_{0}$ and shell thickness $\Delta r$ have complicated forms (Figures 14). In the case of homogeneous NPs of Al with $r_{0}=10 \mathrm{~nm}$ 


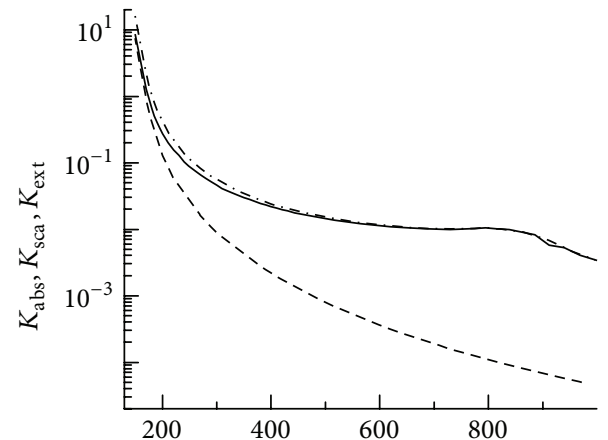

(a)

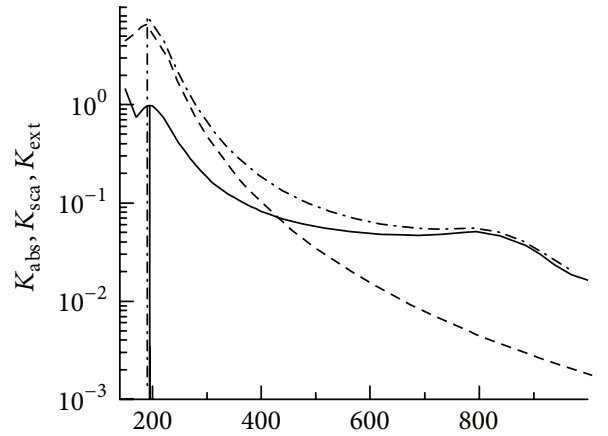

(b)

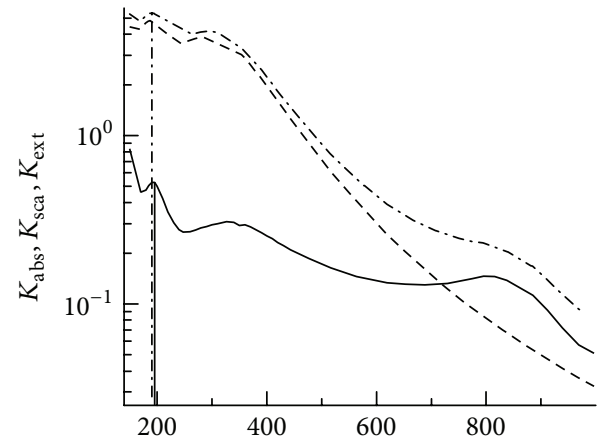

(c)

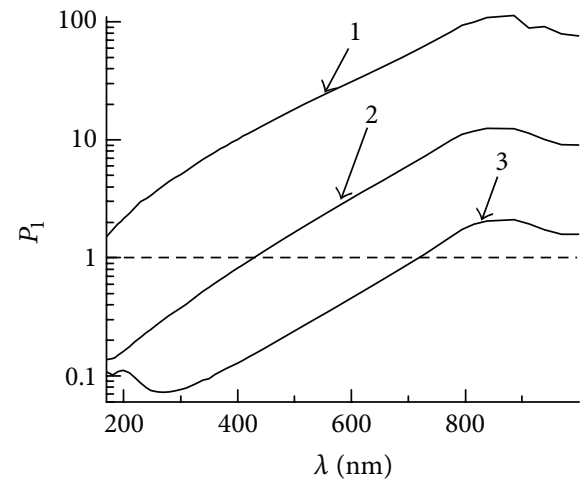

(d)

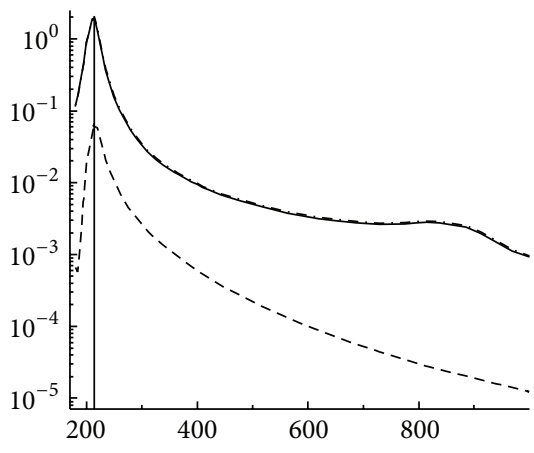

(e)

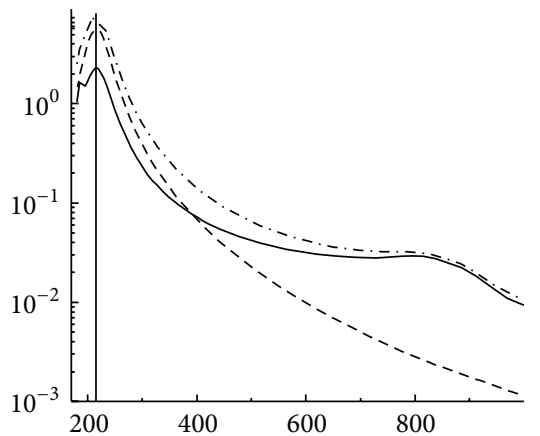

(f)

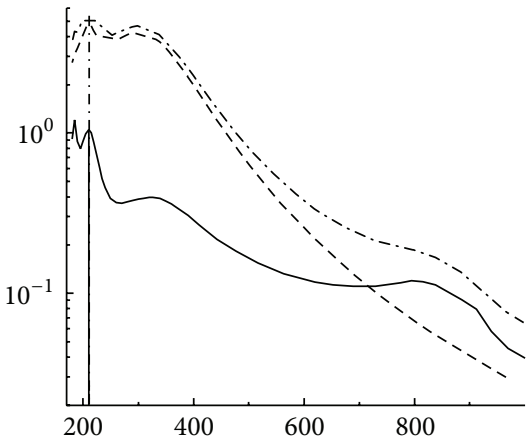

(g)

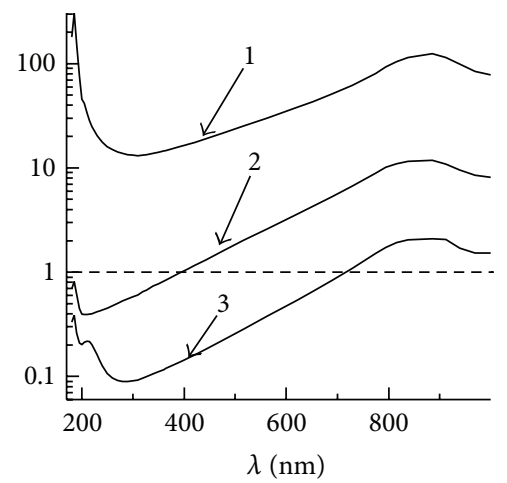

(h)

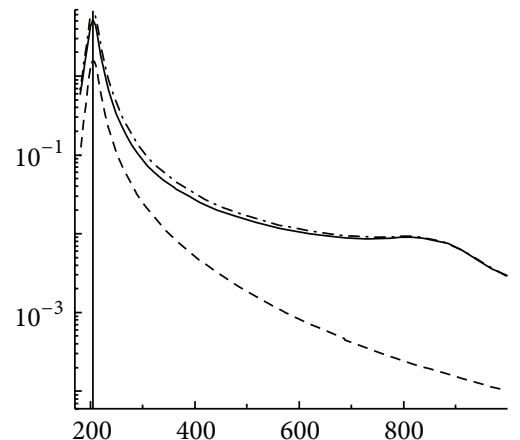

(i)

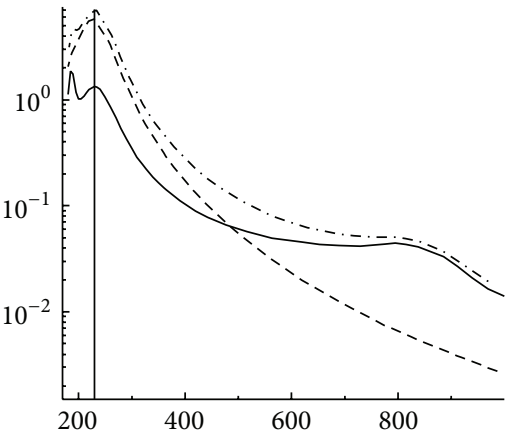

(j)

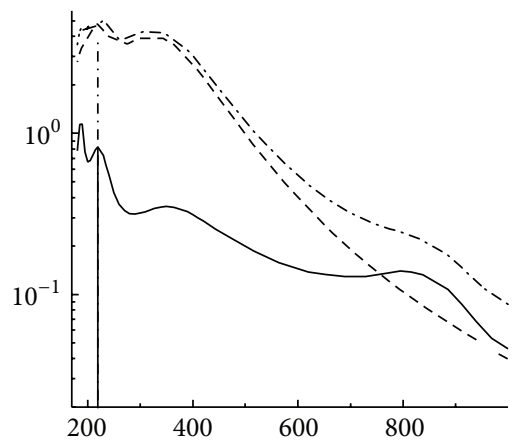

(k)

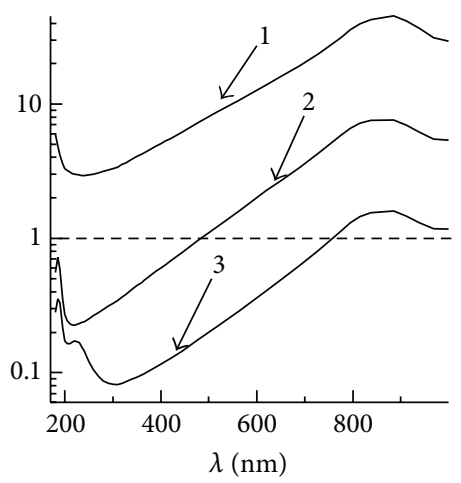

(1)

FIGURE 1: Dependencies of the efficiency factors of absorption $K_{\mathrm{abs}}$ (solid), scattering $K_{\mathrm{sca}}$ (dashed), and extinction $K_{\text {ext }}$ (dashed-dotted) of radiation and parameter $P_{1}$ (solid) on wavelength $\lambda$ for spherical homogeneous Al NPs with radii $r_{0}=10$ (a), 25 (b), and 50 (c) nm, $P_{1}$ for $r_{0}=10$ (1), 25 (2), and 50 (3) nm (d), for two-layered core-shell Al- $\mathrm{Al}_{2} \mathrm{O}_{3} \mathrm{NPs}$ with shell thicknesses $\Delta r_{1}=5 \mathrm{~nm}, r_{0}=5$ (e), 20 (f), and 45 (g) $\mathrm{nm}, P_{1}$ for core-shell NP radii $r_{1}=10(1), 25(2)$, and $50(3) \mathrm{nm}(\mathrm{h})$; for Al- $\mathrm{Al}_{2} \mathrm{O}_{3} \mathrm{NPs}$ with $\Delta r_{1}=5 \mathrm{~nm}$ and $r_{0}=10(\mathrm{i}), 25(\mathrm{j})$, and $50(\mathrm{k}) \mathrm{nm}$, and $P_{1}$ for $r_{1}=15$ (1), 30 (2), and 55 (3) nm (1). NPs are placed in air. 


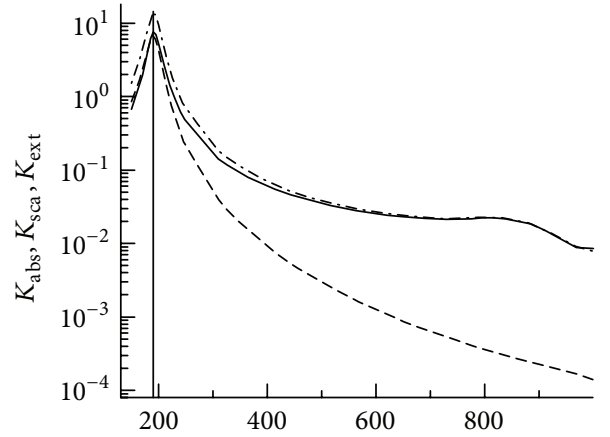

(a)

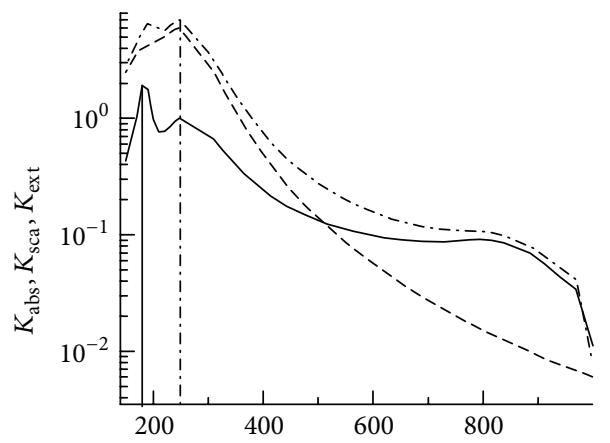

(b)

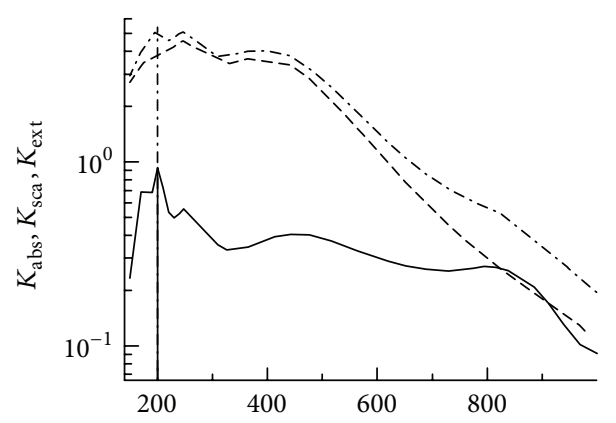

(c)

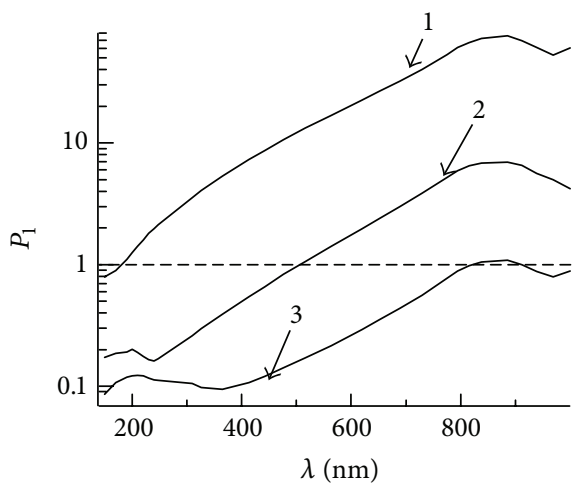

(d)

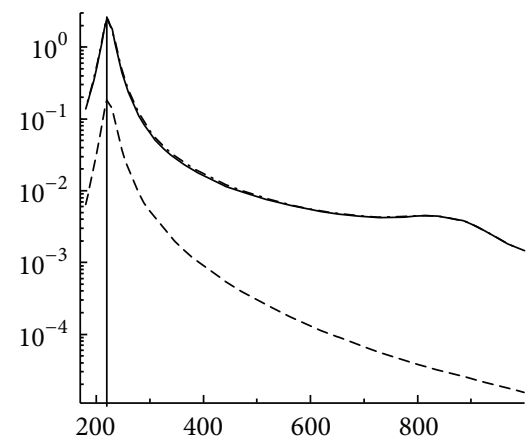

(e)

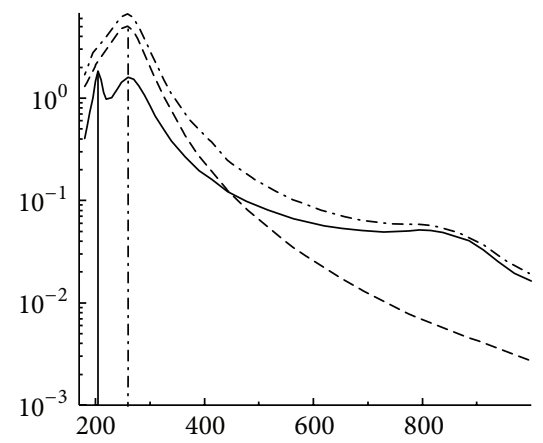

(f)

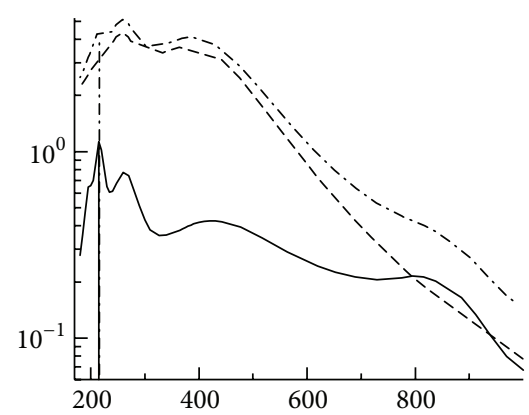

(g)

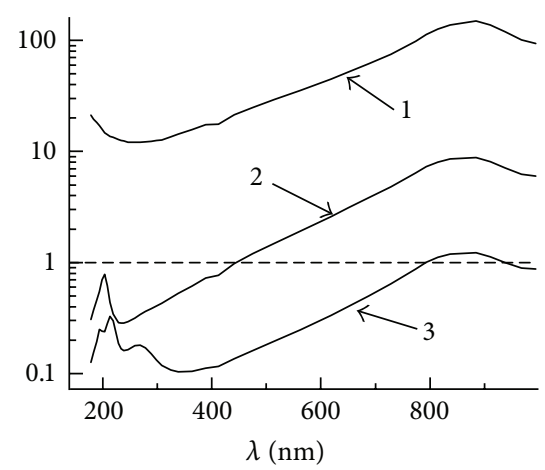

(h)

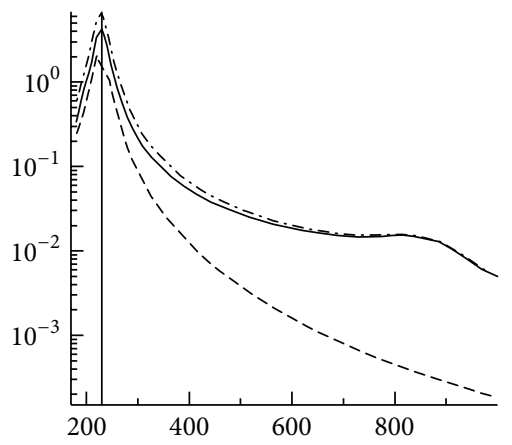

(i)

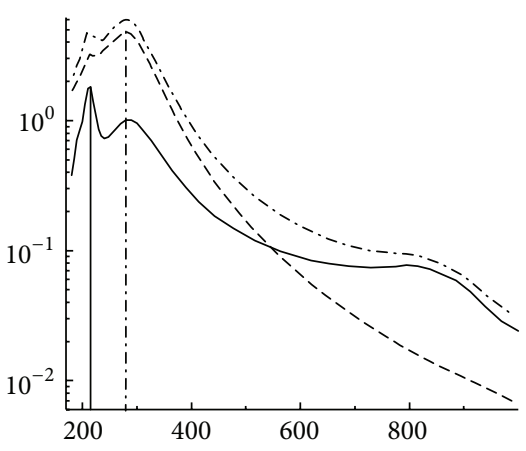

(j)

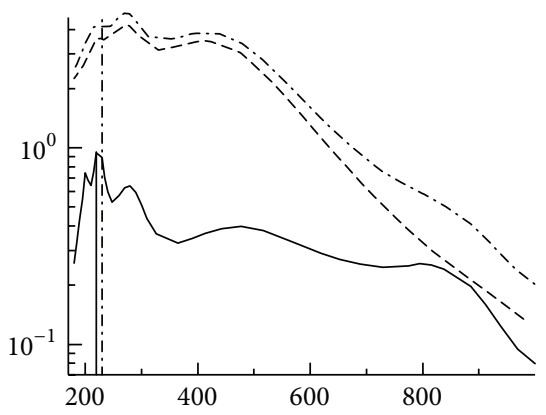

(k)

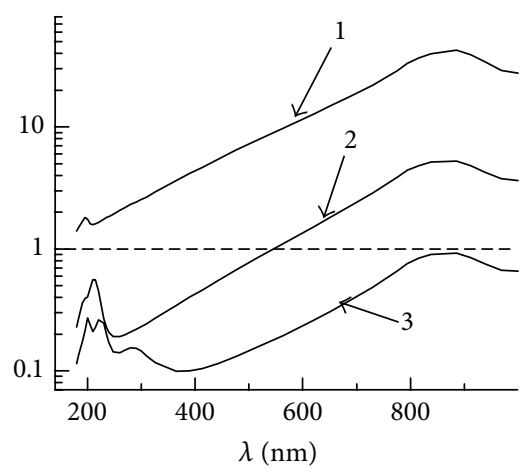

(1)

FIGURE 2: Dependencies of the efficiency factors of absorption $K_{\text {abs }}$ (solid), scattering $K_{\text {sca }}$ (dashed), and extinction $K_{\text {ext }}$ (dashed-dotted) of radiation and parameter $P_{1}$ (solid) on wavelength $\lambda$ for spherical homogeneous Al NPs with radii $r_{0}=10$ (a), 25 (b), and 50 (c) nm, $P_{1}$ for $r_{0}=10$ (1), 25 (2), and 50 (3) nm (d), for two-layered core-shell Al- $\mathrm{Al}_{2} \mathrm{O}_{3}$ NPs with shell thicknesses $\Delta r_{1}=5 \mathrm{~nm}, r_{0}=5(\mathrm{e}), 20$ (f), and 45 (g) $\mathrm{nm}, P_{1}$ for core-shell NP radii $r_{1}=10(1), 25(2)$, and 50 (3) nm (h), for Al- $\mathrm{Al}_{2} \mathrm{O}_{3} \mathrm{NPs}$ with $\Delta r_{1}=5 \mathrm{~nm}$ and $r_{0}=10$ (i), 25 (j), and 50 (k) nm, and $P_{1}$ for $r_{1}=15(1), 30(2)$, and $55(3) \mathrm{nm}(1)$. NPs are placed in water. 


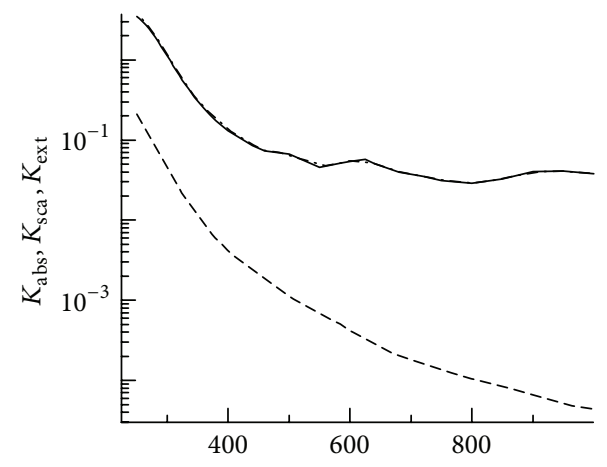

(a)

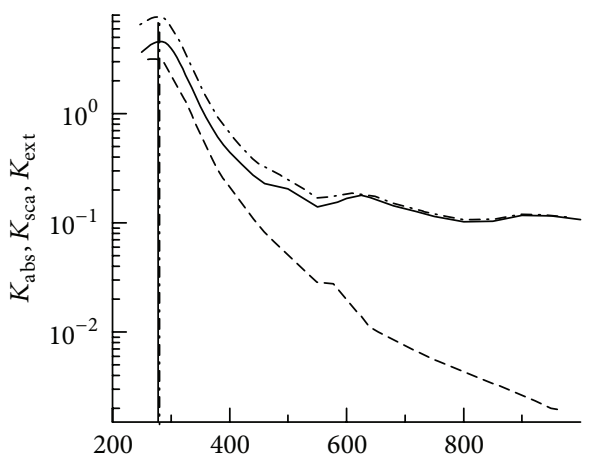

(b)

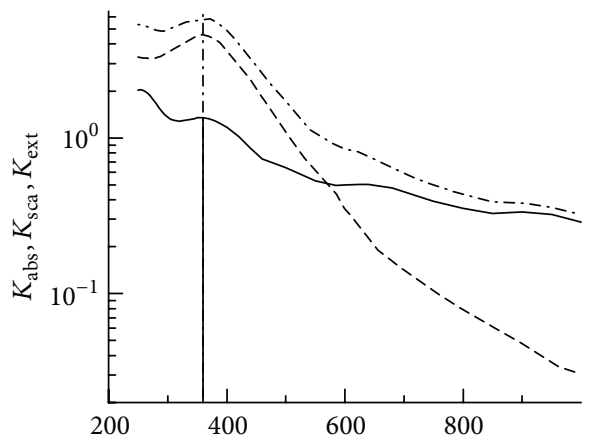

(c)

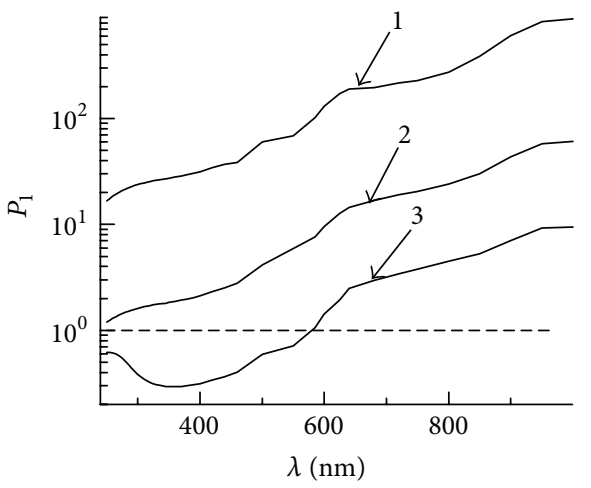

(d)

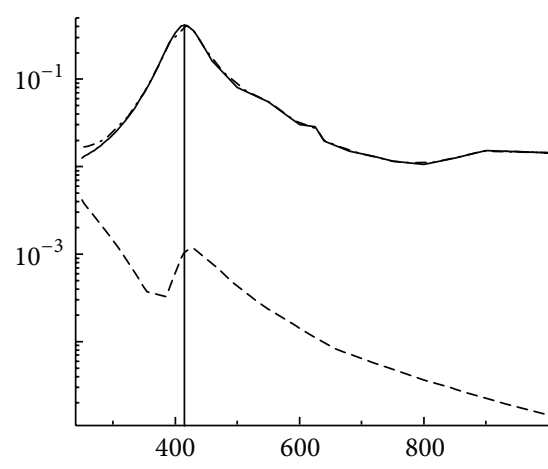

(e)

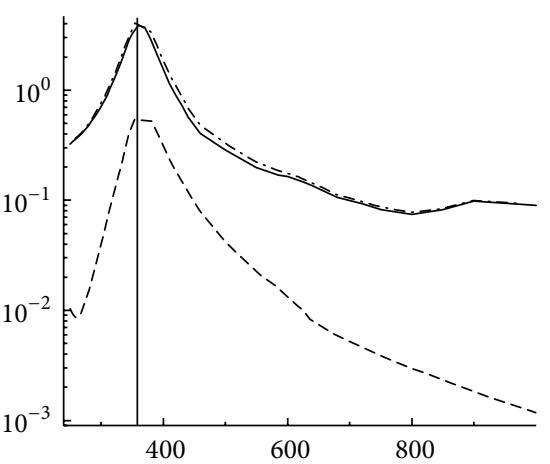

(f)

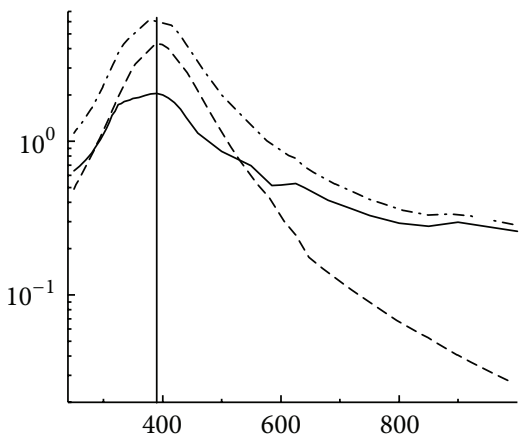

(g)

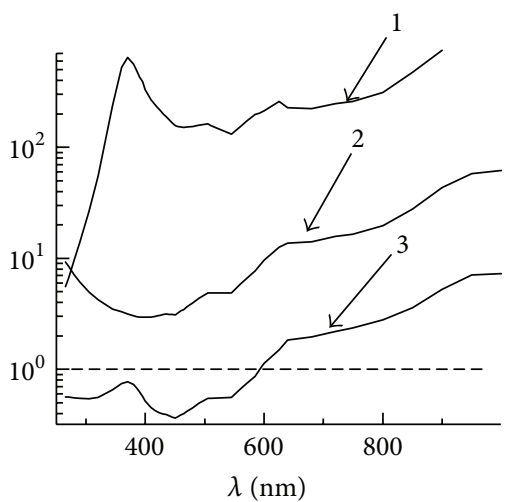

(h)

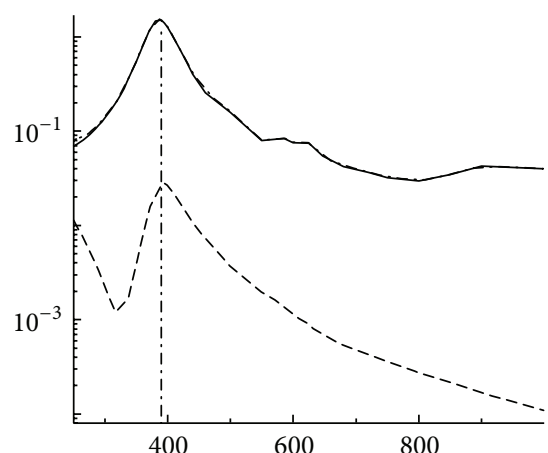

(i)

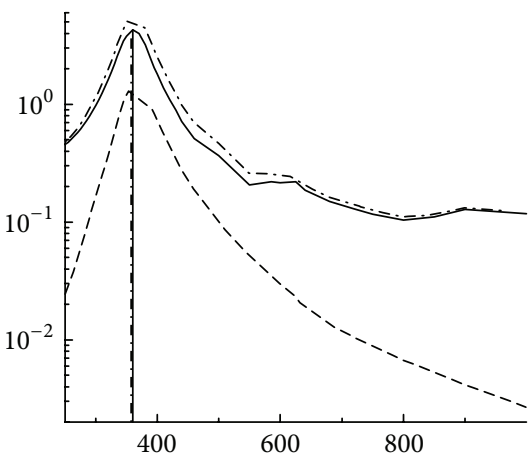

(j)

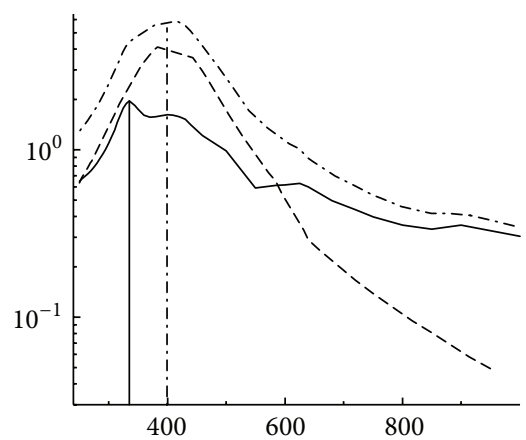

(k)

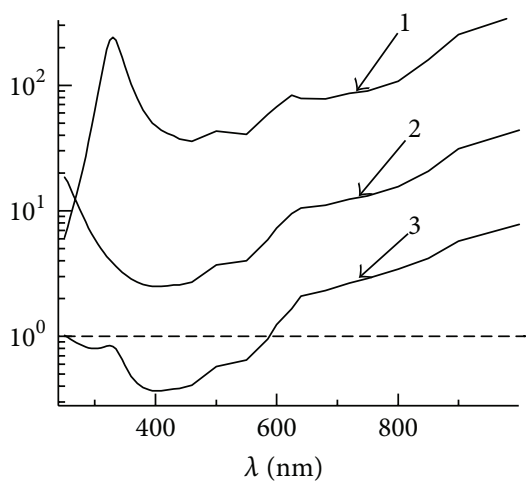

(l)

FIGURE 3: Dependencies of the efficiency factors of absorption $K_{\text {abs }}$ (solid), scattering $K_{\text {sca }}$ (dashed), and extinction $K_{\text {ext }}$ (dashed-dotted) of radiation and parameter $P_{1}$ (solid) on wavelength $\lambda$ for spherical homogeneous Zn NPs with radii $r_{0}=10$ (a), 25 (b), and 50 (c) nm, $P_{1}$ for $r_{0}=10$ (1), 25 (2), and 50 (3) nm (d), for two-layered core-shell Zn-ZnO NPs with shell thicknesses $\Delta r_{1}=5 \mathrm{~nm}, r_{0}=5$ (e), 20 (f), and 45 (g) $\mathrm{nm}, P_{1}$ for core-shell NP radii $r_{1}=10(1), 25(2)$, and 50 (3) nm (h), for Zn-ZnO NPs with $\Delta r_{1}=5 \mathrm{~nm}$ and $r_{0}=10(\mathrm{i}), 25(\mathrm{j})$, and $50(\mathrm{k}) \mathrm{nm}$, and $P_{1}$ for $r_{1}=15(1), 30(2)$, and 55 (3) nm (1). NPs are placed in air. 


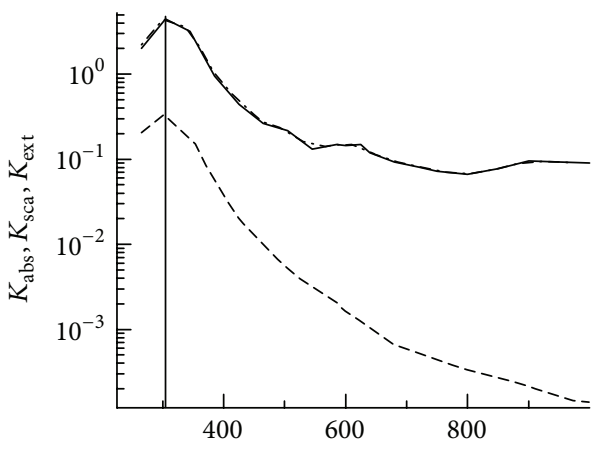

(a)

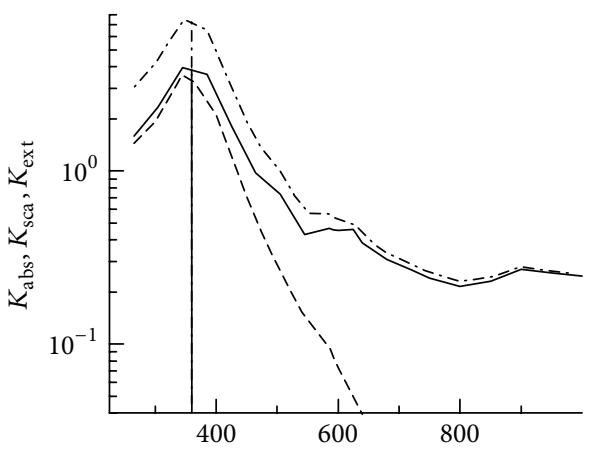

(b)

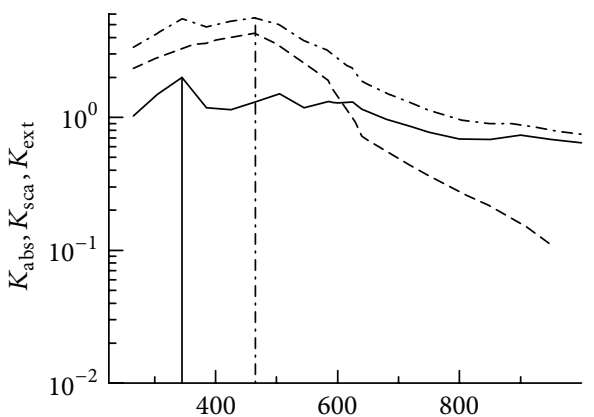

(c)

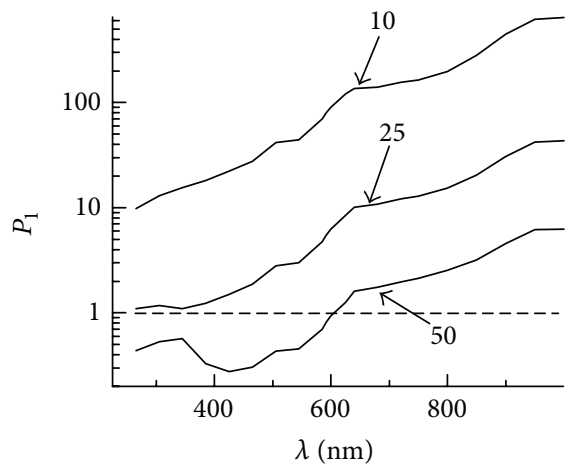

(d)

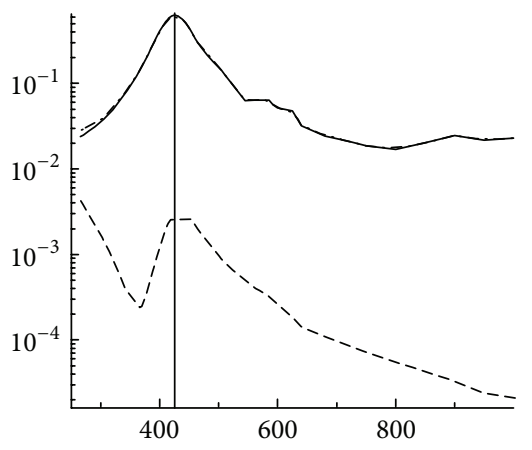

(e)

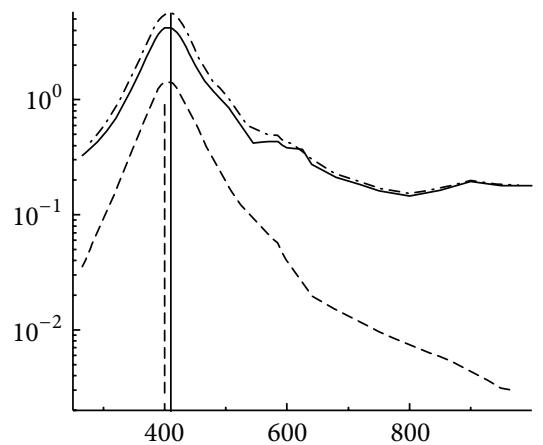

(f)

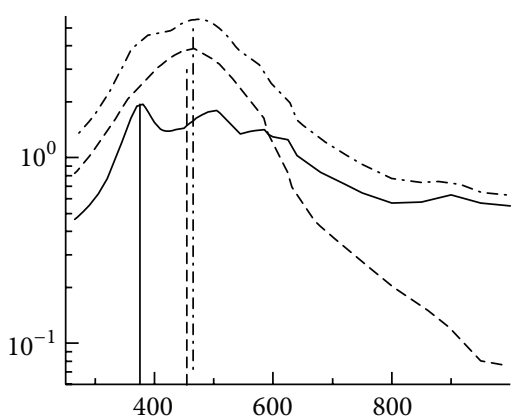

(g)

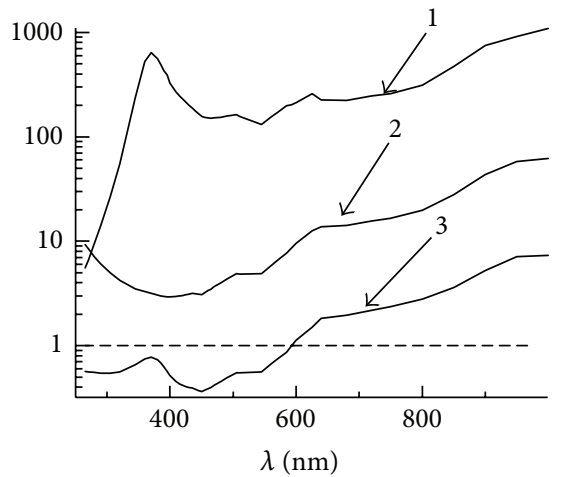

(h)

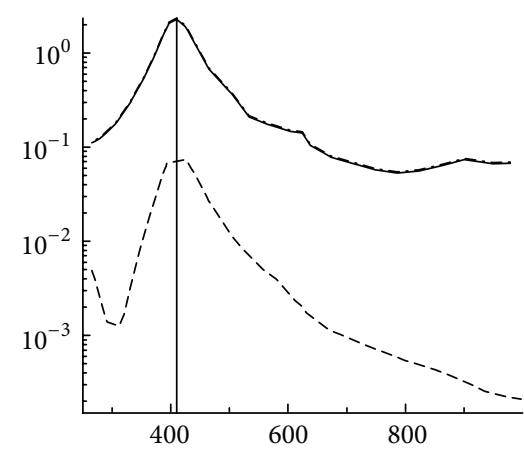

(i)

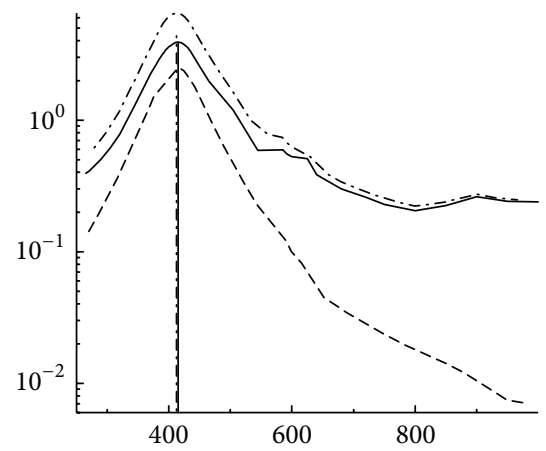

(j)

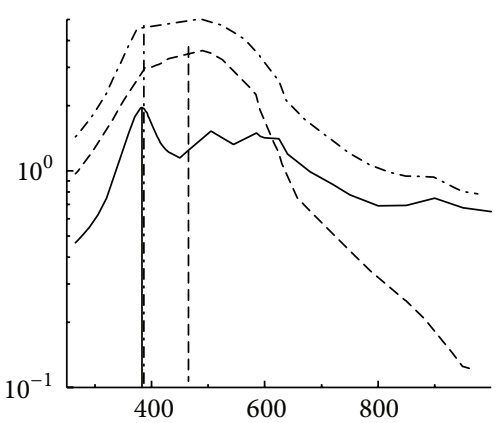

(k)

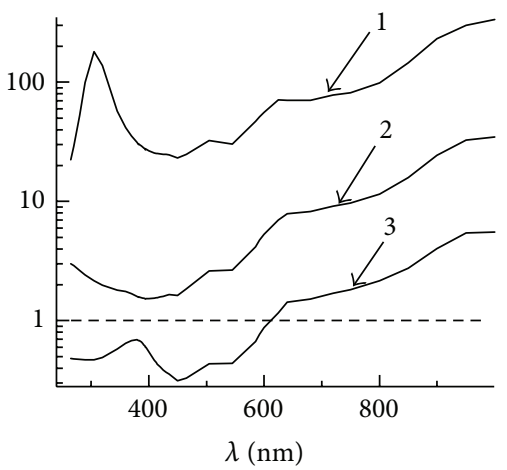

(1)

FIGURE 4: Dependencies of the efficiency factors of absorption $K_{\text {abs }}$ (solid), scattering $K_{\text {sca }}$ (dashed), and extinction $K_{\text {ext }}$ (dashed-dotted) of radiation and parameter $P_{1}$ (solid) on wavelength $\lambda$ for spherical homogeneous Zn NPs with radii $r_{0}=10$ (a), 25 (b), and 50 (c) nm, $P_{1}$ for $r_{0}=10$ (1), 25 (2), and 50 (3) nm (d), for two-layered core-shell Zn-ZnO NPs with shell thicknesses $\Delta r_{1}=5 \mathrm{~nm}, r_{0}=5$ (e), 20 (f), and 45 (g) $\mathrm{nm}, P_{1}$ for core-shell NP radii $r_{1}=10$ (1), 25 (2), and 50 (3) nm (h), for Zn-ZnO NPs with $\Delta r_{1}=5 \mathrm{~nm}$ and $r_{0}=10$ (i), 25 (j), and 50 (k) nm, $P_{1}$ for $r_{1}=15$ (1), 30 (2), and 55 (3) nm (1). NPs are placed in water. 
(Figure 1(a)) there are no maxima in dependencies $K_{\mathrm{abs}}(\lambda)$, $K_{\text {sca }}(\lambda)$, and $K_{\text {ext }}(\lambda)$ in the considered region of wavelengths $150-1000 \mathrm{~nm}$. Formally the maximal values of $K_{\mathrm{abs}}^{\max }$ are placed at $\lambda_{\mathrm{abs}}^{\max }<150 \mathrm{~nm}$. However, for two-layered NP $\mathrm{Al}+\mathrm{Al}_{2} \mathrm{O}_{3}$ (Figure $1(\mathrm{e})$ ) with equal total NP size of $r_{1}=10 \mathrm{~nm}$, consisting of the aluminum core $r_{0}=5 \mathrm{~nm}$ and aluminum oxide shell with thickness $\Delta r_{1}=5 \mathrm{~nm}$, maximums of $K_{\mathrm{abs}}^{\mathrm{max}}$, $K_{\mathrm{sca}}^{\mathrm{max}}$, and $K_{\text {ext }}^{\mathrm{max}}$ arise. Values of $K_{\mathrm{abs}}^{\mathrm{max}}, K_{\mathrm{sca}}^{\mathrm{max}}$, and $K_{\text {ext }}^{\max }$ are placed at the same $\lambda_{\mathrm{abs}}^{\max } \sim 215 \mathrm{~nm}$. It follows that thin oxide shell influences optical properties of two-layered NP. As for homogeneous aluminum NPs with larger radii $r_{0}=25$ (Figure 1(b)) and $50 \mathrm{~nm}$ (Figure 1(c)) appearance of aluminum oxide shell thickness $\left(\Delta r_{1}=5 \mathrm{~nm}\right)$ on the NP surface (Figures $1(\mathrm{f})$ and $1(\mathrm{~g})$ ) leads to small shift of location of $K_{\mathrm{abs}}^{\max }, K_{\mathrm{sca}}^{\max }$, and $K_{\mathrm{ext}}^{\max }$ in the direction of bigger (increasing) wavelengths up to (no more than) $10 \div 25 \mathrm{~nm}$. The values of $K_{\mathrm{abs}}^{\max }$ for two-layered NPs increase with $\sim 50 \div 75 \%$, and the values of $K_{\mathrm{ext}}^{\mathrm{max}}$ increase with $\sim 5 \div 10 \%$.

The formation of oxide shell thickness for $r_{0}=45,50 \mathrm{~nm}$ leads to formation of sharp peak oscillated dependencies with "plato" from wavelength value $150 \mathrm{~nm}$ till 400-450 nm.

Figure 2 presents the dependencies of the efficiency factors of absorption $K_{\text {abs }}$, scattering $K_{\text {sca }}$, and extinction $K_{\text {ext }}$ of radiation and the parameter $P_{1}$ on wavelength $\lambda$ for spherical homogeneous Al NPs with radii $r_{0}=10,25$, and $50 \mathrm{~nm}$ [30]; for two-layered core-shell $\mathrm{Al}-\mathrm{Al}_{2} \mathrm{O}_{3} \mathrm{NPs}$ with shell thicknesses $\Delta r_{1}=5 \mathrm{~nm}$, core radii $r_{0}=5,20$, and $45 \mathrm{~nm}$, and $P_{1}$ for core-shell NP radii $r_{1}=10,25$, and 50; for Al$\mathrm{Al}_{2} \mathrm{O}_{3}$ NPs with $\Delta r_{1}=5 \mathrm{~nm}, r_{0}=10,25$, and $50 \mathrm{~nm}$, and $P_{1}$ for $r_{1}=15,30$, and $55 \mathrm{~nm}$. NPs are placed in water. The data concerning spherical homogeneous $\mathrm{Al}$ NPs with radii $r_{0}=$ 10,25 , and $50 \mathrm{~nm}$, published in [30], are presented here for direct comparison with the results for core-shell $\mathrm{Al}-\mathrm{Al}_{2} \mathrm{O}_{3}$ NPs and determination of the changes contributed by the formation of oxide shells on the surface of metal cores.

The substitution of surrounding medium (air to water) leads to formation of plasmon peaks for homogeneous metal $\mathrm{NP}$ at wavelength $\sim 200 \mathrm{~nm}$ and more pronounced peaks for core-shell NPs with oxide shell. We have to note the shifting of the placements of all optical factors to bigger values of wavelength. The factor of $K_{\mathrm{abs}}^{\max }$ decreases for $r_{0}=10 \mathrm{~nm}$, but for $r_{0}=25$ and $50 \mathrm{~nm}$ there is no decrease in $K_{\mathrm{abs}}^{\max }$ with formation of oxide shell thickness.

Figures 3 and 4 present dependencies of efficiency factors of absorption $K_{\text {abs }}$, scattering $K_{\text {sca }}$, and extinction $K_{\text {ext }}$ of radiation by spherical homogeneous $\mathrm{Zn}$ NPs with radii $r_{0}=$ 10,25 , and $50 \mathrm{~nm}$ [30], two-layered core-shell NPs $\mathrm{Zn}+\mathrm{ZnO}$ with $\Delta r_{1}=5 \mathrm{~nm}, r_{0}=5,20$, and $45 \mathrm{~nm}$, and $P_{1}$ for $r_{0}=5,20$, 45 (h); $\mathrm{Zn}+\mathrm{ZnO}$ NPs with $\Delta r_{1}=5 \mathrm{~nm}$ and $r_{0}=10,25$, and $50 \mathrm{~nm}$ and $P_{1}$ for $r_{0}=10,25$, and 50 (1) on wavelength $\lambda$. NPs are placed in air (Figure 3 ) and in water (Figure 4 ). The data concerning spherical homogeneous $\mathrm{Zn}$ NPs with radii $r_{0}=$ 10,25 , and $50 \mathrm{~nm}$, published in [30], are presented here for direct comparison with the results for core-shell $\mathrm{Zn}+\mathrm{ZnO}$ NPs and determination of the changes contributed by the formation of oxide shells on the surface of metal cores.

The formation of oxide shell with thickness $\Delta r_{1}=5 \mathrm{~nm}$ on core with radius $r_{0}=5 \mathrm{~nm}$ leads to significant decrease of the values of $K_{\mathrm{abs}}, K_{\mathrm{sca}}$, and $K_{\text {ext }}$ in comparison with homogeneous metal NP with $r_{0}=10 \mathrm{~nm}$ and core-shell NP with $r_{0}=10 \mathrm{~nm}$ and $\Delta r_{1}=5 \mathrm{~nm}$.

In Figures 3(a)-3(1) the dependencies of efficiency factors of $K_{\mathrm{abs}}, K_{\mathrm{sca}}$, and $K_{\mathrm{ext}}$ on $\lambda$ are shown for homogeneous NPs of $\mathrm{Zn}$ and two-layered $\mathrm{NP} \mathrm{Zn}+\mathrm{ZnO}$, placed in air. As in the case of homogeneous aluminum NP with radius $10 \mathrm{~nm}$, there are no maxima in dependencies $K_{\mathrm{abs}}(\lambda), K_{\mathrm{sca}}(\lambda)$, and $K_{\text {ext }}(\lambda)$ in the considered region of wavelengths for homogeneous $\mathrm{Zn} \mathrm{NP}$ with radius $10 \mathrm{~nm}$ (Figure 3(a)). But for two-layered $\mathrm{NP} \mathrm{Zn}+\mathrm{ZnO}$ (Figure 3(e)) with equal total NP size of $10 \mathrm{~nm}$, consisting of the $\mathrm{Zn}$ core $\left(r_{0}=5 \mathrm{~nm}\right)$ and $\mathrm{Zn}$ oxide shell with thickness $(\Delta r=5 \mathrm{~nm})$, maxima in the dependencies of absorption, scattering, and extinction on $\lambda$ arise. Values of $K_{\mathrm{abs}}^{\mathrm{max}}, K_{\mathrm{sca}}^{\mathrm{max}}$, and $K_{\mathrm{ext}}^{\mathrm{max}}$ are placed at the same $\lambda_{\mathrm{abs}}^{\max } \sim$ $415 \mathrm{~nm}$. As for homogeneous Zn NPs with larger radii $r_{0}=25$ (Figure 3(b)) and $50 \mathrm{~nm}$ (Figure 3(c)) appearance of Zn oxide shell thickness $\left(\Delta r_{1}=5 \mathrm{~nm}\right)$ on the NP surface (Figures 3(f) and $3(\mathrm{~g})$ ) leads to shift of location of $K_{\mathrm{abs}}^{\max }, K_{\mathrm{sca}}^{\max }$, and $K_{\mathrm{ext}}^{\max }$ in the direction of increasing wavelength by $80 \mathrm{~nm}$ for $r_{0}=$ $25 \mathrm{~nm}$ and by $30 \mathrm{~nm}$ for $r_{0}=50 \mathrm{~nm}$. The values of $K_{\mathrm{abs}}^{\max }$ for $\mathrm{Zn}$ homogeneous and two-layered NPs $\mathrm{Zn}+\mathrm{ZnO}$ for $r_{0}=25 \mathrm{~nm}$ decrease by $\sim 20 \%$, and the values of $K_{\mathrm{sca}}^{\mathrm{max}}$ and $K_{\mathrm{ext}}^{\mathrm{max}}$ increase by $\sim 30 \div 100 \%$. In the case of $\mathrm{Zn}$ homogeneous and twolayered NPs $\mathrm{Zn}+\mathrm{ZnO}$ for $r_{0}=50 \mathrm{~nm} K_{\mathrm{abs}}^{\max }$ and $K_{\mathrm{sca}}^{\mathrm{max}}$ are practically the same, and $K_{\text {ext }}^{\max }$ increases no more than $5 \div$ $10 \%$.

In Figures 3(a)-3(1) the dependencies of efficiency factors of $K_{\mathrm{abs}}, K_{\mathrm{sca}}$, and $K_{\text {ext }}$ on $\lambda$ are shown for homogeneous NPs of $\mathrm{Zn}$ and two-layered $\mathrm{NP} \mathrm{Zn}+\mathrm{ZnO}$, placed in air. As in the case of homogeneous aluminum NP with radius $10 \mathrm{~nm}$, there are no maxima in dependencies $K_{\text {abs }}(\lambda), K_{\text {sca }}(\lambda)$, and $K_{\text {ext }}(\lambda)$ in the considered region of wavelengths for homogeneous $\mathrm{Zn} \mathrm{NP}$ with radius $10 \mathrm{~nm}$ (Figure 3(a)). But for two-layered $\mathrm{NP} \mathrm{Zn}+\mathrm{ZnO}$ (Figure 3(e)) with equal total NP size of $10 \mathrm{~nm}$, consisting of the $\mathrm{Zn}$ core $\left(r_{0}=5 \mathrm{~nm}\right)$ and $\mathrm{Zn}$ oxide shell with thickness $\left(\Delta r_{1}=5 \mathrm{~nm}\right)$, maxima in the dependencies of absorption, scattering, and extinction on $\lambda$ arise. Values of $K_{\mathrm{abs}}^{\mathrm{max}}, K_{\mathrm{sca}}^{\mathrm{max}}$, and $K_{\mathrm{ext}}^{\mathrm{max}}$ are placed at the same $\lambda_{\mathrm{abs}}^{\max } \sim 415 \mathrm{~nm}$. As for homogeneous $\mathrm{Zn}$ NPs with larger radii $r_{0}=25$ (Figure 3(b)) and $50 \mathrm{~nm}$ (Figure 3(c)) appearance of Zn oxide shell thickness $\left(\Delta r_{1}=5 \mathrm{~nm}\right)$ on the NP surface (Figures $3(\mathrm{f})$ and $3(\mathrm{~g})$ ) leads to shift of location of $K_{\mathrm{abs}}^{\max }, K_{\mathrm{sca}}^{\max }$, and $K_{\text {ext }}^{\max }$ in the direction of increasing wavelength by $80 \mathrm{~nm}$ for $r_{0}=25 \mathrm{~nm}$ and by $30 \mathrm{~nm}$ for $r_{0}=50 \mathrm{~nm}$. The values of $K_{\mathrm{abs}}^{\max }$ for $\mathrm{Zn}$ homogeneous and two-layered NPs $\mathrm{Zn}+\mathrm{ZnO}$ for $r_{0}=25 \mathrm{~nm}$ decrease by $\sim 20 \%$, and the values of $K_{\mathrm{sca}}^{\max }$ and $K_{\text {ext }}^{\max }$ increase by $\sim 30 \div 100 \%$. In the case of $\mathrm{Zn}$ homogeneous and two-layered NPs $\mathrm{Zn}+\mathrm{ZnO}$ for $r_{0}=50 \mathrm{~nm} K_{\mathrm{abs}}^{\mathrm{max}}$ and $K_{\mathrm{sca}}^{\mathrm{max}}$ are practically the same, and $K_{\text {ext }}^{\max }$ increase no more than $5 \div$ $10 \%$.

The dependencies of efficiency factors of $K_{\mathrm{abs}}, K_{\mathrm{sca}}$, and $K_{\text {ext }}$ on $\lambda$ for homogeneous NPs of Zn and two-layered NP $\mathrm{Zn}+\mathrm{ZnO}$, placed in water are shown in Figures 4(a)-4(1). As in the case of homogeneous aluminum NP in water with radius $10 \div 50 \mathrm{~nm}$, there are maxima in dependencies $K_{\text {abs }}(\lambda), K_{\text {sca }}(\lambda)$, and $K_{\text {ext }}(\lambda)$ in the considered region of wavelengths for homogeneous Zn NP. For two-layered NP $\mathrm{Zn}+\mathrm{ZnO}$ (Figure $4(\mathrm{e})$ ) with equal total NP size of $10 \mathrm{~nm}$, consisting of the $\mathrm{Zn}$ core $\left(r_{0}=5 \mathrm{~nm}\right)$ and $\mathrm{Zn}$ oxide shell 
with thickness $\left(\Delta r_{1}=5 \mathrm{~nm}\right)$, maxima in the dependencies of absorption, scattering, and extinction on $\lambda$ are shifted more than $100 \mathrm{~nm}$ to increase wavelength. Values of $K_{\mathrm{abs}}^{\max }, K_{\mathrm{sca}}^{\max }$, and $K_{\text {ext }}^{\max }$ are placed at the same $\lambda_{\text {abs }}^{\max } \sim 425 \mathrm{~nm}$. As for homogeneous Zn NPs with larger radii $r_{0}=25$ (Figure 4(b)) and $50 \mathrm{~nm}$ (Figure 4(c)) appearance of $\mathrm{Zn}$ oxide shell thickness $(\Delta r=5 \mathrm{~nm})$ on the NP surface (Figures 3(f) and 3(g)) leads to shift of location of $K_{\mathrm{abs}}^{\mathrm{max}}, K_{\mathrm{sca}}^{\mathrm{max}}$, and $K_{\mathrm{ext}}^{\mathrm{max}}$ in the direction of increasing wavelength by $\sim 50 \mathrm{~nm}$ for $r_{0}=25 \mathrm{~nm}$ and by $\sim 30 \div 50 \mathrm{~nm}$ for $r_{0}=50 \mathrm{~nm}$. The values of $K_{\mathrm{abs}}^{\max }$ for $\mathrm{Zn}$ homogeneous and two-layered NPs $\mathrm{Zn}+\mathrm{ZnO}$ for $r_{0}=25 \mathrm{~nm}$ increase by $\sim 10 \%$, and the values of $K_{\mathrm{sca}}^{\mathrm{max}}$ and $K_{\mathrm{ext}}^{\mathrm{max}}$ decrease by $\sim 20 \div 100 \%$. In the case of $\mathrm{Zn}$ homogeneous and twolayered NPs $\mathrm{Zn}+\mathrm{ZnO}$ for $r_{0}=50 \mathrm{~nm} K_{\mathrm{abs}}^{\max }$ and $K_{\mathrm{sca}}^{\max }$ are practically the same, and $K_{\text {ext }}^{\max }$ decreases no more than $10 \div$ $40 \%$.

The substitution of surrounding medium air to water leads to formation of plasmon peaks for homogeneous metal $\mathrm{NP}$ at wavelength $\sim 300 \mathrm{~nm}$ and more pronounced peaks for core-shell NPs with oxide shell. We have to note the shifting of the placements of all maxima of optical factors to bigger values of wavelength. The factor of $K_{\mathrm{abs}}^{\max }$ increases for $r_{0}=$ $10 \mathrm{~nm}$, but for $r_{0}=25$ and $50 \mathrm{~nm}$ there are no essential changes of $K_{\mathrm{abs}}^{\max }$ with formation of oxide shell thickness.

It is seen from Figures 1-4 that the changes contributed by the appearance and the presence of thin metallic oxide shells on the surface of metallic NPs are essential for small aluminum NPs and all zinc NPs from considered metallic ones. Our results allow estimating the influence of oxide shells appearing on the surface of metallic nanoparticles on absorption, scattering, and extinction of radiation by NPs and influence of ambient properties for their photonic and technological applications.

\section{Conflict of Interests}

The authors declare that there is no conflict of interests regarding the publication of this paper.

\section{References}

[1] J. R. Adleman, D. A. Boyd, D. G. Goodwin, and D. Psaltis, "Heterogenous catalysis mediated by plasmon heating," Nano Letters, vol. 9, no. 12, pp. 4417-4423, 2009.

[2] R. Narayanan and M. A. El-Sayed, "Some aspects of colloidal nanoparticle stability, catalytic activity, and recycling potential," Topics in Catalysis, vol. 47, no. 1-2, pp. 15-21, 2008.

[3] N. I. Zheludev, "Single nanoparticle as photonic switch and optical memory element," Journal of Optics A: Pure and Applied Optics, vol. 8, no. 4, pp. S1-S8, 2006.

[4] Y. Jin, Q. Li, G. Li et al., "Enhanced optical output power of blue light-emitting diodes with quasi-aligned gold NPs," Nanoscale Research Letters, vol. 9, no. 1, pp. 7-13, 2014.

[5] S. Maier, Plasmonics: Fundamentals and Applications, Springer, New York, NY, USA, 2007.

[6] M. I. Stockman, "Nanoplasmonics: past, present, and glimpse into future," Optics Express, vol. 19, no. 22, pp. 22029-22106, 2011.
[7] H. A. Atwater and A. Polman, "Plasmonics for improved photovoltaic devices," Nature Materials, vol. 9, no. 3, pp. 205-213, 2010.

[8] A. Govorov and H. Richardson, "Generating heat with metal NPs," Nanotoday, vol. 2, pp. 30-39, 2007.

[9] V. K. Pustovalov, L. G. Astafyeva, and W. Fritzsche, "Selection of thermo-optical parameter of nanoparticles for achievement of their maximal thermal energy under optical irradiation," Nano Energy, vol. 2, no. 6, pp. 1137-1141, 2013.

[10] N. J. Halas, "The photonic nanomedicine revolution: let the human side of nanotechnology emerge," Nanomedicine, vol. 4, no. 4, pp. 369-371, 2009.

[11] L. C. Kennedy, L. R. Bickford, N. A. Lewinski et al., "A new era for cancer therapy: gold NP-mediated thermal therapies," Small, vol. 7, no. 2, pp. 169-183, 2011.

[12] X. Huang, P. K. Jain, I. H. El-Sayed, and M. A. El-Sayed, "Plasmonic photothermal therapy (PPTT) using gold nanoparticles," Lasers in Medical Science, vol. 23, no. 3, pp. 217-228, 2008.

[13] V. K. Pustovalov, A. S. Smetannikov, and V. P. Zharov, "Photothermal and accompanied phenomena of selective nanophotothermolysis with gold nanoparticles and laser pulses," Laser Physics Letters, vol. 5, no. 11, pp. 775-792, 2008.

[14] A. Csaki, F. Garwe, A. Steinbrück et al., "A parallel approach for subwavelength molecular surgery using gene-specific positioned metal nanoparticles as laser light antennas," Nano Letters, vol. 7, no. 2, pp. 247-253, 2007.

[15] J. Wang, J. D. Byrne, M. E. Napier, and J. M. Desimone, "More effective nanomedicines through particle design," Small, vol. 7, no. 14, pp. 1919-1931, 2011.

[16] V. Pustovalov, L. Astafyeva, and B. Jean, "Computer modeling of the optical properties and heating of spherical gold and silica-gold nanoparticles for laser combined imaging and photothermal treatment," Nanotechnology, vol. 20, no. 22, Article ID 225105, 2009.

[17] V. K. Pustovalov, L. G. Astafyeva, E. Galanzha, and V. P. Zharov, "Thermo-optical analysis and selection of the properties of absorbing nanoparticles for laser applications in cancer nanotechnology," Cancer Nanotechnology, vol. 1, no. 1-6, pp. 35-46, 2010.

[18] S. Inasawa, M. Sugiyama, S. Noda, and Y. Yamaguchi, "Spectroscopic study of laser-induced phase transition of gold nanoparticles on nanosecond time scales and longer," Journal of Physical Chemistry B, vol. 110, no. 7, pp. 3114-3119, 2006.

[19] V. K. Pustovalov, "Theoretical study of heating of spherical nanoparticle in media by short laser pulses," Chemical Physics, vol. 308, no. 1-2, pp. 103-108, 2005.

[20] H. Muto, K. Miyajima, and F. Mafuné, "Mechanism of laserinduced size reduction of gold nanoparticles as studied by single and double laser pulse excitation," Journal of Physical Chemistry C, vol. 112, no. 15, pp. 5810-5815, 2008.

[21] J. Wang, Y. Chen, X. Chen, J. Hao, M. Yan, and M. Qiu, "Photothermal reshaping of gold nanoparticles in a plasmonic absorber," Optics Express, vol. 19, no. 15, pp. 14726-14734, 2011.

[22] M. Honda, Y. Saito, N. I. Smith, K. Fujita, and S. Kawata, "Nanoscale heating of laser irradiated single gold NPs in liquid," Optics Express, vol. 19, no. 13, pp. 12375-12383, 2011.

[23] A. Stalmashonak, G. Seifert, and A. Abdolvand, Ultra-Short Pulsed Laser Engineered Metal-Glass Nanocomposites, Springer, New York, NY, USA, 2013.

[24] V. K. Pustovalov and A. S. Smetannikov, "Analytical and computer modelling of thermal processes of laser interaction 
with a single nanoparticle," RSC Advances, vol. 4, no. 99, pp. 55760-55772, 2014.

[25] U. Kreibig and M. Vollmer, Optical Properties of Metal Clusters, vol. 25 of Springer Series in Material Science, Springer, Heidelberg, Germany, 1995.

[26] C. F. Bohren and D. R. Huffman, Absorption and Scattering of Light by Small Particles, John Wiley \& Sons, New York, NY, USA, 1983.

[27] V. K. Pustovalov and V. A. Babenko, "Optical properties of gold nanoparticles at laser radiation wavelengths for laser applications in nanotechnology and medicine," Laser Physics Letters, vol. 1, no. 10, pp. 516-520, 2004.

[28] M. Pelton, J. Aizpurua, and G. Bryant, "Metal-nanoparticle plasmonics," Laser \& Photonics Reviews, vol. 2, no. 3, pp. 136$159,2008$.

[29] Y. Sonnefraud, A. L. L. Koh, D. W. McComb, and S. A. Maier, "Nanoplasmonics: engineering and observation of localized plasmon modes," Laser and Photonics Reviews, vol. 6, no. 3, pp. 277-295, 2012.

[30] V. K. Pustovalov, L. G. Astafyeva, and W. Fritzsche, "Plasmonic and thermo-optical properties of spherical metallic NPs for their thermo-plasmonic and photonic applications," Journal of Nanoparticles, vol. 2014, 15 pages, 2014.

[31] L. R. Hirsch, A. M. Gobin, A. R. Lowery et al., "Metal nanoshells," Annals of Biomedical Engineering, vol. 34, no. 1, pp. 1522, 2006.

[32] A. Guerrero-Martínez, J. Pérez-Juste, and L. M. Liz-Marzán, "Recent progress on silica coating of nanoparticles and related nanomaterials," Advanced Materials, vol. 22, no. 11, pp. 11821195, 2010.

[33] M. B. Cortie and A. M. McDonagh, "Synthesis and optical properties of hybrid and alloy plasmonic nanoparticles," Chemical Reviews, vol. 111, no. 6, pp. 3713-3735, 2011.

[34] M. R. Jones, K. D. Osberg, R. J. MacFarlane, M. R. Langille, and C. A. Mirkin, "Templated techniques for the synthesis and assembly of plasmonic nanostructures," Chemical Reviews, vol. 111, no. 6, pp. 3736-3827, 2011.

[35] V. K. Pustovalov and D. S. Bobuchenko, "Heating, evaporation and combustion of a solid aerosol particle in a gas exposed to optical radiation," International Journal of Heat and Mass Transfer, vol. 32, no. 1, pp. 3-17, 1989.

[36] F. Ruffino, G. Piccitto, and M. G. Grimaldi, "Simulations of the light scattering properties of metal/oxide/core/shell nanospheres," Journal of Nanoscience, vol. 2014, Article ID 407670, 11 pages, 2014.

[37] K. Laaksonen, S. Suomela, S. R. Puisto, N. K. J. Rostedt, T. Ala-Nissila, and R. M. Nieminen, "Influence of high-refractiveindex oxide coating on optical properties of metal nanoparticles," Journal of the Optical Society of America B: Optical Physics, vol. 30, no. 2, pp. 338-348, 2013.

[38] G. Valverde-Aguilar, J. A. García-Macedo, and V. RenteríaTapia, "Silver core-silver oxide shell nanoparticles embedded on mesostructured silica films," Journal of Nano Research, no. 3, pp. 103-114, 2008.

[39] J. M. J. Santillán, L. B. Scaffardi, and D. C. Schinca, "Quantitative optical extinction-based parametric method for sizing a single core-shell Ag- $\mathrm{Ag}_{2} \mathrm{O}$ nanoparticle," Journal of Physics D: Applied Physics, vol. 44, no. 10, Article ID 105104, 2011.

[40] Z. Yang, L. He, J. Chen, H. Cong, and H. Ye, "Microstructure and

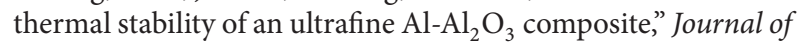
Materials Research, vol. 18, no. 2, pp. 272-278, 2003.
[41] Y.-J. Peng, S.-P. Zhang, Y.-H. Wang, and Y.-Q. Yang, “Theoretical investigation on near-infrared and visible absorption spectra of nanometallic aluminium with oxide coating in nanoenergetic materials: Size and shape effects," Chinese Physics B, vol. 17, no. 9, pp. 3505-3511, 2008.

[42] S. Das, S. Datta, A. K. Mukhopadhyay, K. S. Pal, and D. Basu, "Al- $\mathrm{Al}_{2} \mathrm{O}_{3}$ core-shell composite by microwave induced oxidation of aluminium powder," Materials Chemistry and Physics, vol. 122, no. 2-3, pp. 574-581, 2010.

[43] J. E. Martin, A. A. Herzing, W. Yan et al., "Determination of the oxide layer thickness in core-shell zerovalent iron nanoparticles," Langmuir, vol. 24, no. 8, pp. 4329-4334, 2008.

[44] H. Zeng, Z. Li, W. Cai, B. Cao, P. Liu, and S. Yang, "Microstructure control of $\mathrm{Zn}-\mathrm{ZnO}$ core/shell nanoparticles and their temperature-dependent blue emissions," Journal of Physical Chemistry B, vol. 111, no. 51, pp. 14311-14317, 2007.

[45] T. Ghodselahi, M. A. Vesaghi, and A. Shafiekhani, "Study of surface plasmon resonance of $\mathrm{Cu} @ \mathrm{Cu}_{2} \mathrm{O}$ core-shell nanoparticles by Mie theory," Journal of Physics D: Applied Physics, vol. 42, no. 1, Article ID 015308, 2009.

[46] E. Grigor'ev and E. Meilikhov, Physical Quantities, Atomizdat, Moscow, Russia, 1991, (Russian).

[47] P. B. Johnson and R. W. Christy, "Optical constants of the noble metals," Physical Review B, vol. 6, no. 12, pp. 4370-4379, 1972.

[48] E. D. Palik, Handbook of Optical Constants of Solids, Academic Press, New York, NY, USA, 1998.

[49] SOPRA N\&K Database, http://refractiveindex.info. 

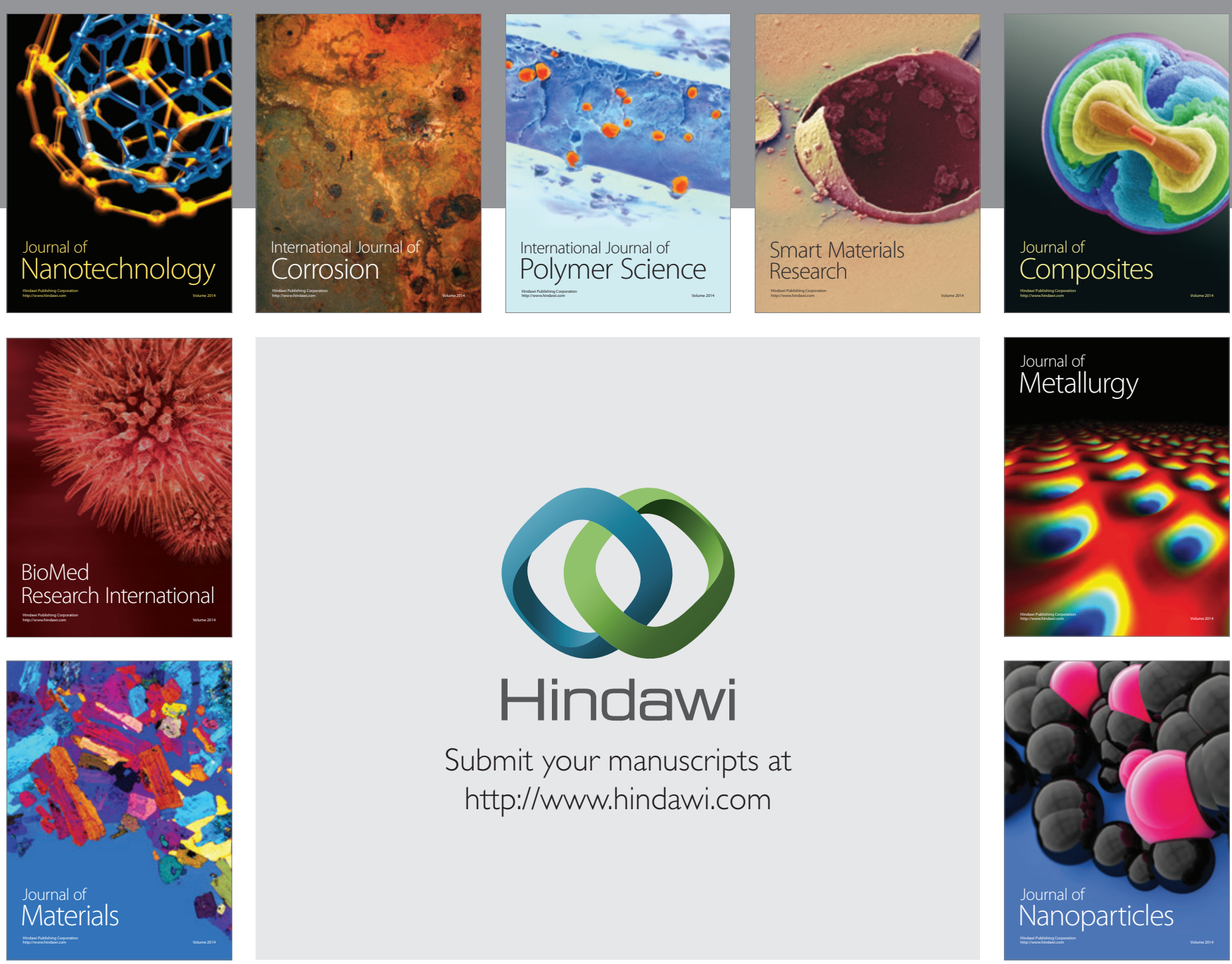

Submit your manuscripts at http://www.hindawi.com
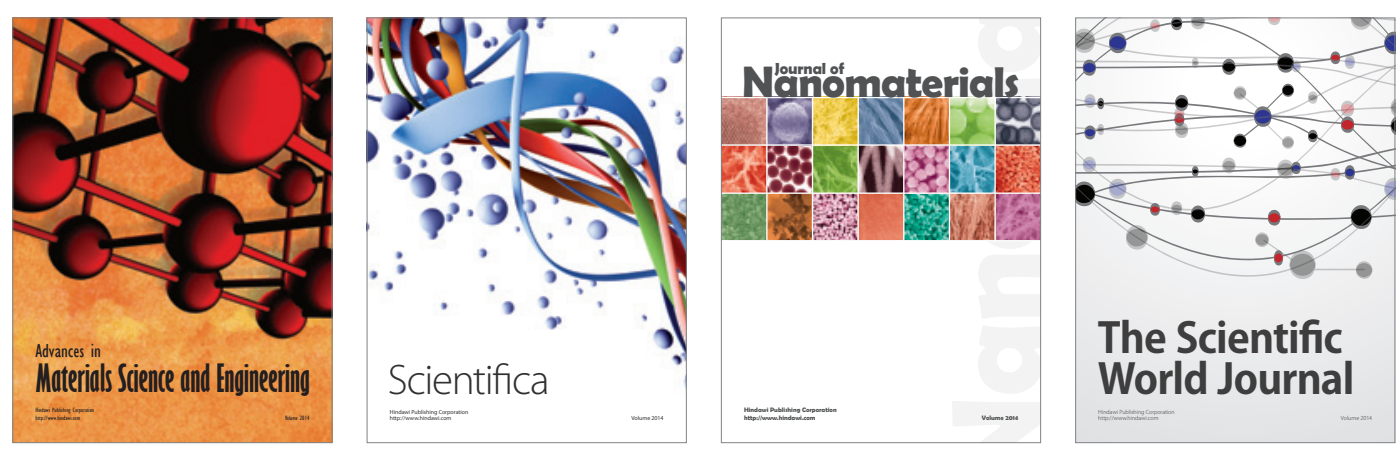

\section{The Scientific World Journal}
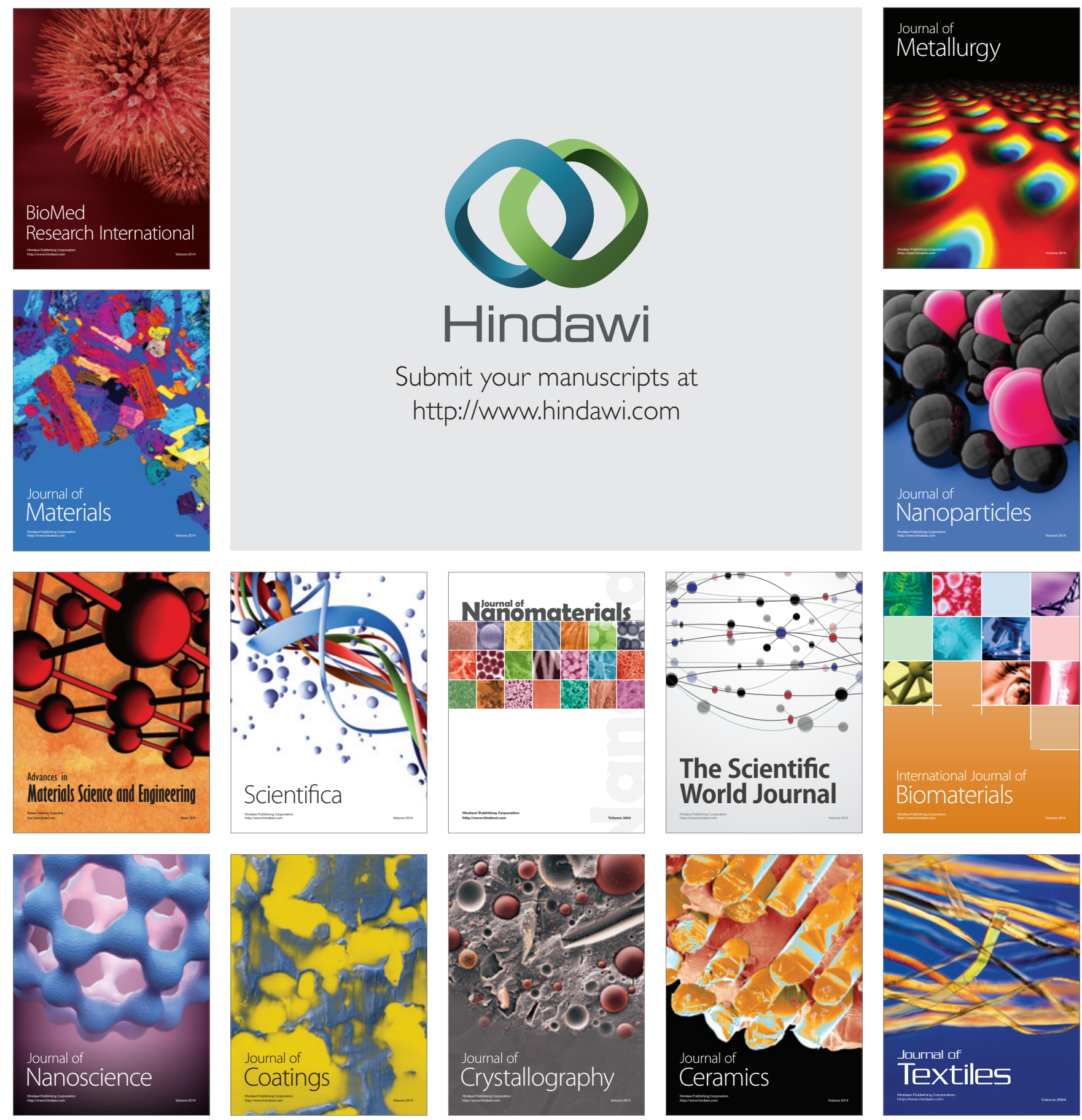